\title{
Profiling to Improve Control: Conflicts and Aggressive Behaviour Regulation by Elite Referees
}

\author{
Grégoire Duvant, Williams Nuytens \\ Faculty of Sport and Physical Education, Artois University, URePSSS, SHERPAS, Liévin, France
}

Email address:

gregoire.duvant@univ-artois.fr (G. Duvant),williams.nuytens@univ-artois.fr (W. Nuytens)

\section{To cite this article:}

Grégoire Duvant, Williams Nuytens. Profiling to Improve Control: Conflicts and Aggressive Behaviour Regulation by Elite Referees. International Journal of Sports Science and Physical Education. Vol. 5, No. 3, 2020, pp. 21-34. doi: 10.11648/j.ijsspe.20200503.11

Received: May 4, 2020; Accepted: June 23, 2020; Published: September 21, 2020

\begin{abstract}
Research question. This paper examines the activity of referees. More precisely, it studies the regulation of interactions, game circumstances and aggressive and punishable behaviours by elite handball referees in France. This article deals with the management of individuals on the pitch by the referee. It seeks to answer an important question in the field of the regulation of behaviors and management of individuals: what are the tools and strategies used by referees to regulate behaviour? Research methods. Through a field survey that relied on direct observations of the activity of referees, ethnographic interviews, and immersion, the paper offers a description of the refereeing activity without fragmenting it into different competencies. Results and findings. Taking into account the component of refereeing such as physical performance, perception, decision-making and communication, three profiles have been established and presented to the reader: the consensual referee, the rule-following referee and the perceptive referee. Implications. These profiles help us grasp the regulatory activity developed by the referees: the activity draws on multiple sources in response to the deviance phenomenon which had multiple causes and factors.
\end{abstract}

Keywords: Activity, Regulation, Aggressive Behaviour, Referee, Handball, Elite

\section{Introduction}

What's a referee? What does refereeing involve? Researchers, both specialized and non-specialized in sports, have been asking the question. Sociology and the Frenchspeaking literature rarely examine refereeing as a complex system, and instead focus on its separate components. The international literature shows some heuristic differences in how it approaches refereeing, by breaking up the competencies of the "sports judges". Competency can be defined as the set of potential behaviours that allows an individual to perform effectively a complex activity. It involves knowledge, expertise and interpersonal skills [1]. That is to say a competency combines declarative knowledge, procedural knowledge and attitudes [2,3]. Refereeing is not studied as a complex system, its founding components are compartmentalised and studies as separate entities. That approach has advantages, such as the ability to drill down on a competency and to draw more precise scientific conclusions; but it is also limiting. A segmented view of refereeing is not conducive for strong interests in aggressive behaviours and their regulation. Aggressive behaviours and their regulations is a multifactorial process that requires taking into account several dimensions. That is why we chose to study refereeing in its global and complex nature to avoid drawing wrong conclusions based on variables that are not adequate enough to explain the differentiating elements from the non-differentiating elements when it comes to the regulation of aggressive behaviours. We deliberately chose to go beyond the limits of a segmented approach of the refereeing activity. We are aware that taking everything into account is not possible. Therefore, our more global approach to refereeing triggers several questions: what methodology should we follow? What dimensions should we retain? How can we select them? Our proposed global approach thus implies taking risk; it is a deliberate choice, an attempt to try to describe how referees regulate aggressive behaviours. The segmented analysis of refereeing has its advantages, but its limits compel us to adopt a different approach. 


\subsection{The Segmented Approach of the Refereeing: Benefits and Limits}

Under this approach, refereeing is divided in four core components that together describe the activity of a referee: physical performance, perceptions, decisions and communication.

Some authors view refereeing as possessing a physical stamina and an athletic condition that meet the standards of the sports' governing bodies [4-6]. Others describe the activities of a referee in terms of positions and movement speed that result in a performance [7,3]. The referee must above all display a strong physical performance, which ensures that he is always well-positioned to make his decisions.

Refereeing consists of collecting, sorting and processing information to make decisions. The referee's perceptions is the basis of many works, such as the link between perception and decision-making in handball [9]; tackling diving in football [10]; or the link between perception and ball trajectory prediction in cricket [11]. These various studies show the significance of good perception in the activity of the referee.

Decision-making and its context were largely studied in English-speaking literature. Many works showed that practice and repetition improve the quality of decisionmaking [12-13]. Others emphasize the influence of context on the choices of the referee or the judges, such as the order of appearance in synchronized swimming [14], the citizenship of the athlete or the judge in figure skating [15]. or the noise of the crowd in football stadiums [16-19]. Therefore, the decision-making process is one of the core components of refereeing. Errors in that process may affect the athletes and the outcome of the match [20].

Communication activity is also one of the components of refereeing. It improves the referee-players interaction. When used strategically, it may be linked to the prevention of behaviours punished by the rules [21]. Communication improves the relationship between referees, players and coaches, which is necessary to prevent incidents during the match [22]. Therefore, interactions and communication activity are at the heart of refereeing. They play a decisive role [23].

The segmented approach has ensured the development a fine and technical body of knowledge or answers to precise questions. For instance, some authors showed that home advantage is real, both in football [24], in boxing [25] or in rugby [26]. The referees' decisions are more favourable to the home team. The researchers' initial interrogation was simple: does the team or the athlete benefit from home advantage? Answering that question required a research protocol that segmented the activity of the referee. Segmentation allowed a consolidation of sharp, precise and technical knowledge that a global approach of refereeing would be unable to construct. It allows to clarify hypotheses and to test them. Segmentation ensures a sharper description, a more detailed and more thorough analysis of one of the components of refereeing.
Therefore, it has many benefits. It unveils both the smooth and the rough edges that a researcher following a globalized approach would miss, as his analysis may not have enough depth. Yet the segmented approach also has limits and drawbacks. A survey of the literature shows that many researchers adopt a hypothetico-deductive model and start their studies with precise questions and hypotheses. Such approach may lead to methodological biases, particularly when studying aggressive behaviours and deviance. The production of aggressive behaviours or deviance is multifactorial [27]. Therefore, a segmented approach and the use of the hypothetico-deductive model are inadequate to grasp the multiple causes of deviance or its multiple dimensions. It thus appears that a more global approach of refereeing may be more appropriate.

\subsection{A More Global Approach of Refereeing}

In his book L'épreuve du terrain, Williams Nuytens showed that the actors involved in sports activities have a segmented vision of the situations and of the activity [28]. Such a vision relates to the status of the person. Thus a player thinks and sees things like a player. A club executive perceives the situations and thinks like a club executive. The same paradigm applies to the referee; however he must also open up his vision to the other actors and adapt his assessment of the circumstances. Nuytens therefore invites us to consider the complexity of the situations and interactions when studying referees. In the same fashion, other authors argue in favour of a global analysis of refereeing, such that the activity of the referee is not seen as an accumulation of tasks but instead as a complex activity that should be approached as such [29].

Thus we aim to describe the activities of referees on the field, to assess and understand what they are doing. The later is a co-construction that involves not only the referee but also the other actors [30]. We have therefore taken into consideration the referees-players interactions to describe what these "sports judges" do. Interactions may indeed explain some events happening in the pitch, such as whether aggressive behaviours are exhibited or not [31]. The activity of the referee develops in relation to the interacting players. We decided to focus precisely on the management of aggressive and behaviours punishable by the rules to describe the activity of the referee. Aggressive behaviours refer to physical or verbal actions taken against another person in order to harm them. Aggressive and punishable behaviour, which is the focus of this study, applies when such actions are forbidden by the rules and the perpetrator may face punishment. Several reasons explain that focus. First of all, choosing aggressive behaviours as the main point helps to stay close to the foundation of refereeing: interactions. Secondly, the choice is justified by the fact that for the governing bodies of sports and the sports specialists, the referee is above all the symbol of behavioural regulation: his main mission is to protect the players and to prevent injuries. Furthermore, aggressive behaviours are the driver of sport [32]. An analysis of these behaviours is an attempt to 
understand what happens at the core of sports activities. Finally, concentrating on behaviour management ensures that the activity of the referee is not segmented, since it involves physical performance, perception, decision-making and communication.

We consider both the events occurring during the matchinstrumented violence - and behaviours aiming to physically and morally injure the opponent-hostile violence [33]. Therefore we are including offensive and defensive violent actions $[34,35,36]$, and predatory and quarrelsome violent actions $[37,38]$. Consequently, our study encompasses all the behaviour targeted at the opponent and punishable by the rules. We focus on a specific activity: handball. Handball is characterized by physical contact, prehension and one-to-one situations. Handball's intrinsic qualities thus allow an examination of the regulation of interactions, situations and aggressive behaviours. We could have chosen a different sport such as football-which exhibits more aggressive behaviours [39]. - but we do not wish to focus exclusively on these behaviours. We want to study the interactions and situations that may result in aggressive behaviours. Handball seems a more heuristic approach because of its intrinsic qualities.

Literature shows that referees are entrusted with two main missions: guarantee the safety of the athletes on the field and regulate the players' aggressive behaviours. We aim to study the link between the referees and behaviour management. This requires us to conduct a literature survey on these two topics.

\section{Literature Survey}

\subsection{Guarantee the Safety of the Athletes}

The referees protect the athletes and aim to lower the risk of injuries, as evidenced by the studies on this topic even if they did not cover handball specifically. For instance, some researchers studied the causes of injuries during the 1994 football World Cup [40]. Even if the decisions of the referee are not responsible for the injuries, half of the injuries result from a physical contact between players. Therefore, injuries are often arising from interactions, thus requiring the referee to pay special attention to them. Others have targeted the link between player injuries and rules violations in the Norwegian professional football championship [41]. The authors tried to answer the question "are the referees doing their jobs?" and discovered that the "men in black" have the capability to act in order to lower the risk of injuries. The referees can act and compel a change of behaviour. Therefore, refereeing is an activity of regulations.

\subsection{Regulate the Interactions and Behaviours of Players}

Regulation is a concept that allows to describe the multiple exchanges between individuals in the pitch. Regulation means coordinating the relationships between individuals with opposing agendas, such as the athletes, and to perform adjustments on the actions and interactions happening on the pitch [42]. to provide the individuals the experience of a more appeased match. Regulation can use multiple levers. Regulation can be defined as adjustments; arrangements between the rules of law and the de facto rules; compromises between formal rule and actual practice; differences between prescription and reality [43]. Regulation is therefore made of negotiations and manifests through different shapes [44]. On the pitch, the referee embodies regulation [45] develops varied strategies.

Disciplinary actions, and more globally repressive methods, are a lever of regulation. The referees try to influence the match and the players' behaviours by punishing more or less severely: by being sparing with yellow cards [46] or through a systematic use of punishments.

The referee may also regulate through education. Education allows the referees to develop prevention. Hence, to increase the safety of ice hockey players, the "men in black" believe that the coach is the most suited to educate his players and make it so that the latter's behaviours does not compromise the safety of the other players on the ice rink [47]. The referees recommend safety awareness education to make ice hockey safer and to protect the players' physical integrity.

Behaviour regulation may also rely on changes in how the refereeing activity is performed. The referee's positioning affects the detection, identification and management of situations. A change in positions of the officials in the NFL led to the identification of new offences in the field [48].

Regulation can also take advantage of strategies specific to a country. The football players' behaviour change depending on the country where they are playing: Spain, Italy or England. Furthermore, the results show that the referees have started to change their preparation and their activities in order to adapt to the behavioural specificities of each countries [49].

Without being exhaustive, one can find many sources of regulations for referees: repressive methods and use of disciplinary action to deal with the situations, prevention by education, changes in how the activity of the referee is performed or intercultural responses. The diversity of these activities of regulation is indicative of an activity of social control, which standard dimensions were studied by Maurice Cusson [50], who listed several sources of social control, including: reprimand, informal punishments, tolerance, stigmatization, dissuasion, labelling.

\section{Methods}

An analysis of refereeing by focusing on the protection of players and the regulation of the interactions does not imply that it is compartmentalized based on the competencies. Indeed, all the competencies that the referee has acquired are working towards these two goals. So how can interactions and behaviours be regulated to ensure that the players experience a more appeased athletic context? What strategies do the referees deploy? What does the refereeing activity entail? 
Our work aims to answer these questions through an analysis of the refereeing activity that takes into account the core components of elite refereeing as set forth in the literature: physical performance, perceptions, decisions and communication. This work is unique because it combines all of these components. Such grouping of the core components of refereeing is possible only because we are studying one of the many activities of the referee: the regulation of aggressive behaviour. A study of the refereeing activity as a whole would instead have led to issues and methodological biases.

As mentioned before, the handball referees were the subjects of our research. We studied the top two divisions of the French national championships: the LNH - Ligue Nationale de Handball (National League of Handball), which became the "Lidl Star Ligue" and the PROD2, which was renamed "Proligue" for the men's championships; the LFH Ligue Féminine de Handball (Women's League of Handball) and the D2F - Women's Division 2, for the women's championship. We surveyed 19 referee pairs from the G1 group (LNH/LFH/PROD2) and 24 referee pairs from the $\mathrm{G} 2$ group (D2F).

The choice of elite referees is justified by the fact that these individuals are perfectly in control of their environment and can describe their activity; and they are able to discuss and assess what they are doing on the field. They are experts. Their activity has become a professional activity. They developed tools, strategies and actions to conduct their activity. Expertise results in ease of expression and in-depth content thanks to the accumulation of many skills, as shown by the works on experts in a specific field, such as best workers in France [51] or food critics [52].

We attempted to describe the activities that the referees perform. Our paper does not purport to provide comprehensive definitions of all the strategies that may be deployed. We intend to highlight the most widespread behaviours and to build systematic knowledge in order to establish typical profiles of referees. Mainly, we tried to describe the content of the players-referees interactions so as to discover profiles that clarify the complexity of refereeing and regulation of behaviours. The description of profiles is the result of the combination of observation and interviews with the referees, two complementary tools in sociological studies [53]. Therefore, we observed 129 matches for 43 referee pairs.

Observations consist in gathering information across three observables: the people present in the observed location, the events and actions that form and unfold there and which belong to a temporality and a location, as well as the situations [54]. The referees were not informed of our presence. Such "incognito" observations ensure that what we gather in our descriptions correspond to what really happens in the field [55]. Additionally, the referees are less tempted to change their usual behaviour. They will not mistake our role as observers with that of an inspector [56]. Our work is mostly to describe without being seen, to meet the actors and collect their words, and to play a role that match our goals while also being acceptable for the subjects of the survey [57]. "Incognito" observation ends when we start the interviews. The later involves face-to-face meetings, and the way we would introduce ourselves to the referees has been carefully planned. We decided to keep the actual motivations of the research and its content rather vague. We did not want the referees to censure themselves and to give us a speech in line with the official expectations of their hierarchical body. We did not emphasize our ties with the Federation in order to avoid being seen as its spy.

Our work consisted of direct observations [56] from the stands, hidden from prying eyes. We took notes, noticed elements of descriptions or context. The purpose was to perceive the situations and create a narrative [58]. At the end of the period of observation, we went to the referees' locker room to talk about the actions, the choices and how they embody their activity. We discussed with the referees once the matches have ended. The interview included looking back at the observables and the elements described during the match in order to gather the meaning the referees gave to their actions. Called ethnographic interview, the objective of this type of interview is to evaluate what we saw and to connect that with what really happened in the field. It is thus essential to try to answer to the questions "how" and "why" did the events happened?

The dual work of observation and ethnographic interviews helped us build referee profiles that involve different modes of regulation of interactions. We then finalized our survey by selecting a referee pair for each profile and undergoing a month long immersion period during which we remained with the referees from their home to the location of the matches, and were with them at all times during their activity: in the locker rooms before and after the matches, during the debriefs with the referee assessor if there was one, to remain with them for the pre-match meeting with the match commissioner and the team representatives... Such immersion ensures closeness with the actors. It gives access to what remains "invisible" when we stay in the stands. However, this tool requires that there is enough distance to overcome the biases of excessive closeness and the drawbacks of a participating observation [59]. We attempted to describe what we saw, heard and experienced in order to deepen the construction of knowledge about the modes of regulation that the referees use [60].

The method that we described includes several research techniques: direct observation, ethnographic interview and immersion period. These techniques complement each other and allow pinpointing behaviours, patterns and outliers. The complementary nature relies on caution and attention, as we were not under the best possible circumstances when it comes to evaluating the refereeing activity. The availability of body cameras and microphones would probably have brought additional value to the survey. Without these tools, we tried to cross-reference the findings in order to investigate the heart of refereeing. As a result, we established referee profiles by systematizing our discoveries on the field in order 
to put forth ideal types inherited from Max Weber's method. We took inspiration from the process by which ideal types are drawn to build systematic profiles that are more or less representative of reality. The profiles set out in this paper does not exist strictly speaking, they are the result of a simplification of reality. Ideal type offers a simplified version of reality, "purified from contingent variations" [61]. They are constructs [62] that allows a better understanding of the direction followed by the individuals.

The survey established a typology of referee profiles that took into account the components of elite refereeing: physical performance, perceptions, decisions and communication. Such typology was built based on Hirschman's model [63] which defines four responses that an individual can exhibit when facing a situation: exit, voice, loyalty and neglect $[64,65]$. The person may run away, leave or flee the situation (exit), oppose and challenge it (voice), remain and take action with selfrestraint (loyalty) or withdraw passively (neglect). The model has been amended and enriched lately through the addition of the oppositions between destructive and constructive behaviours and passive and active behaviours [66]. That model can be related to the Sainsaulieu's typology of professional identities [67], in which the individuals have the choice between retreat, community, affinity and negotiation. These modelling processes are useful in the development of a typology of referees; yet they are not complete. Indeed, they claim that individuals make rational choices and always decide based on costadvantage assessment, but that is not always the case.

The model of individual adaptation of Merton [68] was also one of the starting points of our work on referees. It sets out five modes of adaptation in order for the individuals to reach their goals: conformity, ritualism, innovation, retreatism and rebellion. Even though that typology is incomplete and unfinished, it establishes a sense of the activity of the individual and deserves a special interest in our survey.

Our proposed typology relies on three referee profiles that arise from our field research and literature in order to understand the regulatory activity of the "men in black": the consensual referees, the rule-following referees, and the perceptive referees.

\section{The Results}

\subsection{The Consensual Referees}

\subsubsection{The Less Noticed We Are, the Better"- Christian" ${ }^{1}, 46$ Years Old}

These referees take a back seat away from the game and from situations of conflict. They position themselves far from the interactions and stay in the background on the pitch. Such decision result from the referee's willingness to not hinder the match. The "sports judge" disappears in order to allow the

\footnotetext{
${ }^{1}$ All the names have been changed to protect the anonymity of the interviewed referees.
}

players to express their potential. The referees want to avoid breaking the flow of the game by their untimely or premature actions. They are middlemen whose mission is to promote the show, and that is manifested through a certain distance from the game. Christian, a G2 group referee, establishes a link between a position away from interactions and the desire to promote the show:

'We move and position ourselves so that the game can be alive. And sure... perhaps we are a bit too far... but that's our way of livening up the game, we don't want to hinder anyone... After all, we're also there to support the show, not to ruin it. So the less noticed we are, the better'.

Christian, 46 years old, G2 referee

The referees support the show and deploy a strategy to achieve that goal. Their positioning is not only a reflection of how they view and embody the activity of a referee; it also provides clues on the mode of regulation of interactions and behaviours. For instance, the consensual referee's stationary positioning implies a specific regulation. The referee deals with the situations once they have happened. The physical performance of the "men in black" implies a "reactive" refereeing.

\subsubsection{We Move to Deal with the Circumstances" Hubert, 49 Years Old}

The referee is motivated by a motivation to repress the behaviours that may affect the players' physical integrity. The "sports judges" move toward the area of conflicts, not to send a preventive message to the players but to punish them. The connection between motion and repression is a foundation of the activity of a consensual referee. He does not believe that motion as means of prevention is effective. Hubert, a G2 group referee, draws the line between motion and disciplinary actions:

'I don't really see the usefulness of always moving on the pitch. We move to deal with problematic circumstances. In short, we go toward the action when we have to punish, otherwise we remain in our position. Doing otherwise won't provide any additional benefit... We're asked to move more... but wouldn't that be moving for the sake of it? It's useless... It doesn't make sense'.

Hubert, 49 years old, G2 referee

The referees move only in case of necessity. Giving a punishment requires moving in order to better single out the player to be punished. Furthermore, the lack of preventionmotivated motions helps to better understand that the referees want to stay in the background to promote the show and protect their credibility.

\subsubsection{We Protect Ourselves (...) We Don't Expose Ourselves" - Serge, 44 Years Old}

The consensual referee does not want to expose himself and refrains from making decisions that may lead to conflicts. Therefore, he aims to protect himself by being less active than his peers from the other profiles and abstains from making decisions that may alter the outcome of the match. He chooses to not act, even to the point of establishing a "laissez-faire". In many circumstances, he 
chooses not to take a decision. Serge, a G2 group referee, would rather not intervene and take decisions in order to avoid disputes:

'When you see the things that happened in the past... all the scandals... we... we'd rather not intervene. That allows us at least to protect ourselves... we don't expose ourselves.'

Serge, 44 years old, G2 referee

Not taking a decision prevents them from making incorrect choices that might lead to protests or to conflicts. Making a decision is taking a risk. Conversely, not making a decision is to protect oneself. The determination to protect oneself is reflected in concrete situations during which the referee refrains from intervening. Some conflicting circumstances require the physical presence of the referee, and yet the referee deliberately chooses to not move. He favours selfregulation. He believes that the players can alter their unlawful behaviours by themselves, without his intervention. Two episodes that occurred during a match between Union Sportive and the Sporting show the referee's noninterventionism policy:

'01'25: defender $\mathrm{B} 11^{2}$ is late. He catches the arm of B7, which was about to score. The two referees do not react; they remain away from the action. The field referee is motionless near the middle lane. The field referee whistles from where he is positioned. He doesn't run toward the area of conflict, he is not present. The referees stay away from the area of conflict.

03'58: player A27 holds the ball when he is stopped by two players who corner him from a side, from behind, to prevent him from scoring. This frustrates A27, who utters words to his opponent defenders, face to face, head against head. The referees do not intervene. The field referee whistles from the position where he was before the episode happened.

05'15: player B2 commits a foul on A11. He grabs A11's jersey from behind, preventing him from advancing toward the goal. The field referee does not go into the conflict area. He gives a yellow card to B2 to punish him, from his current position, i.e. near the middle line.'

Excerpts from research notes, match between

Union Sportive and Sporting ${ }^{3}$ (LNH)

The referees do not intervene when a situation of interaction becomes tense. They chose to avoid taking the risk of acting prematurely.

\subsubsection{There's the Rules, and There's What you do with Them"- Patrick, 50 Years Old}

The consensual referee's decisions do not always result from the rules. Patrick, a G1 group referee, explains that when he is refereeing, his decision-making is instant and the rules are only of secondary importance:

'We try to be as neutral as possible, but the truth is we usually decide on a case by case basis. I can't tell you how I

\footnotetext{
${ }^{2}$ A refers to the home team, and $\mathrm{B}$ to the visiting team. The number refers to the player. For instance, B11 indicates a player from the visiting team that wears the jersey number 11 .

${ }^{3}$ Just like the players, the names of the clubs were also changed.
}

would react to such or such circumstance... It's a decision on the spot... when something happens; you have to make a decision, right there. And that's it! So there are the rules, and there's what you do with them.'

Patrick, 50 years old, G1 referee

The decision-making activity of a consensual referee can be identified through two characteristics. First, the choices do not arise from neutral and precise criteria and do not rely on events that may be observed, singled out and transposable under other circumstances. Therefore, it is an opaque decision-making. The referee frees himself from the rules to make his decisions. Second, the use of disciplinary actions is not consistent. The referee does not follow the principle of "one foul, one decision, one punishment". The same foul will trigger different responses from the referee. The perception activity of the consensual referee may partially explain the differences in how he processes the various stages of the game.

\subsubsection{We try to Pay Attention to Everything. " Ludovic, 52 Years Old}

The activity of perception of the consensual referees is not defined in advance. The two referees (field referee and goal referee) have no prior division of labour. Information gathering happens randomly and globally. The strategy used for this component of refereeing is counter to the principles set out by the governing body. The latter recommends that the goal referee gathers information around the goal area and evaluates the intensity of the fight deployed by the pivots. The referee is supposed to collect clues that allow the appraisal of the balance of power around the goal line. Beyond that, the activity of perception is also formed on a lack of precise criteria and tools. The referee cannot see everything. Wanting to monitor everything results in a lack of respect of each referee's area of influence and a feeling of domination between the referee pair. We can see that in the words of Ludovic, a G1 group referee.

'We try to pay attention to everything... even to the smallest details... Yes, we also miss things... But what are you going to do? We try to catch everything (...) And that's how sometimes we're intervening in the other's turf... (Laughs). We're supposed to let the other take charge... but sometimes I'm faster than him, or the opposite.'

Ludovic, 52 years old, G1 referee

Beyond the division of tasks on the field, the referees that belong to this profile do not gather information based on precise criteria or elements. For instance, there are signs that allow a referee to decide to give a disciplinary punishment or not. The criteria are listed in the rules: the part of the body affected by the foul, the intensity of the physical contact, the effect on the victim (was the player able to continue his action? Did he fall? Was he injured?), the position of the defender (was he from the front, from the side or from behind?). Consensual referees do not use these elements. These "sports judges" believe that using decision criteria would limit their attention, and therefore reject these tools. 


\subsubsection{Communication... Uses It... not Misuse It"- Charles, 55 Years Old}

Consensual referees have a special use of communication. They do not communicate to prevent behaviours or conflicts. The referee believes that his interventions are unnecessary and that the players may change their behaviours by themselves. The player must adapt to the referees, and not the opposite. Charles, a G1 group referee, talks about how he views communication:

'For me, you must know how to use communication... not misuse it. You have to realize that the players are smart enough to understand the decisions... There's no need to repeat the same things time and again to them...'

Charles, 55 years old, G1 referee

Thus the "men in black" always reject the use of communication as preventive measure. Situations of communications are scarce. The referees send a message and do not expect any feedback. Paradoxically, the communication is built on the rejection of exchanges and reciprocity. The players who try to communicate with the referee are given a disciplinary action. The "sports judges" do not wish to grant the players the possibility of expressing themselves, even during short exchanges. Punishing the players when they try to talk to the referee is a proof of the one-way communication that the referees try to build. For them, it is a way to establish or to reiterate their authority. It strengthens the interaction inside which they operate. The interaction is asymmetric since one side-the pair of referees - decides on behalf of everyone. The roles cannot be switched. Ending the activity of communication is a deliberate action used to delineate the distance between the referees and the player. When a consensual referee directs a match, a dominant-dominated relationship exists.

Multiple actors determine the quality of a match. Refereeing is the result of interactions with the players, the coaches, the spectators... So the referee is not the only actor capable of regulating the circumstances. He relies on selfregulation. The referees from this profile believe that the players should be the first ones to deal with the interactions or the events during the match.

\section{CONSENSUAL REFEREE}

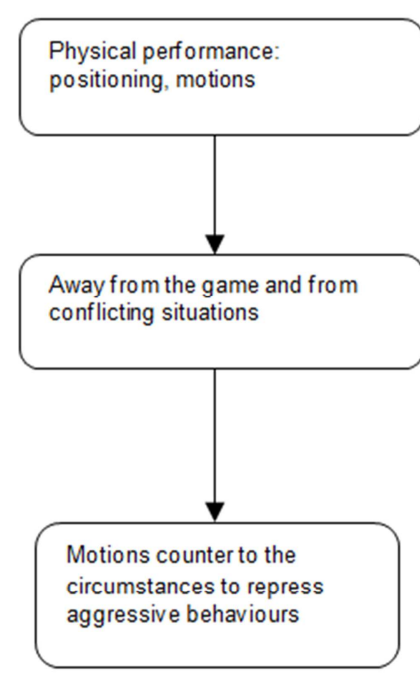

\subsection{The Rule-following Referees}

\subsubsection{We Need to be Where Things Happen"- Olympe, 49 Years Old}

The referees try to be as close as possible to the situations of conflict. They always chose a position near the action in order to be able to intervene as quickly as possible when an issue arises. Their physical performance is combined with a dynamic behaviour, as illustrated by an alert position. The "men in black" stand on their toes or make short lateral motions (like a windscreen wiper) to be always ready to act. They will not remain static in a remote position; they are operating in the middle of the area where the play occurs and use their activity to minimize the risks of reprehensible aggressive behaviours. The "sports judge" seeks to deploy

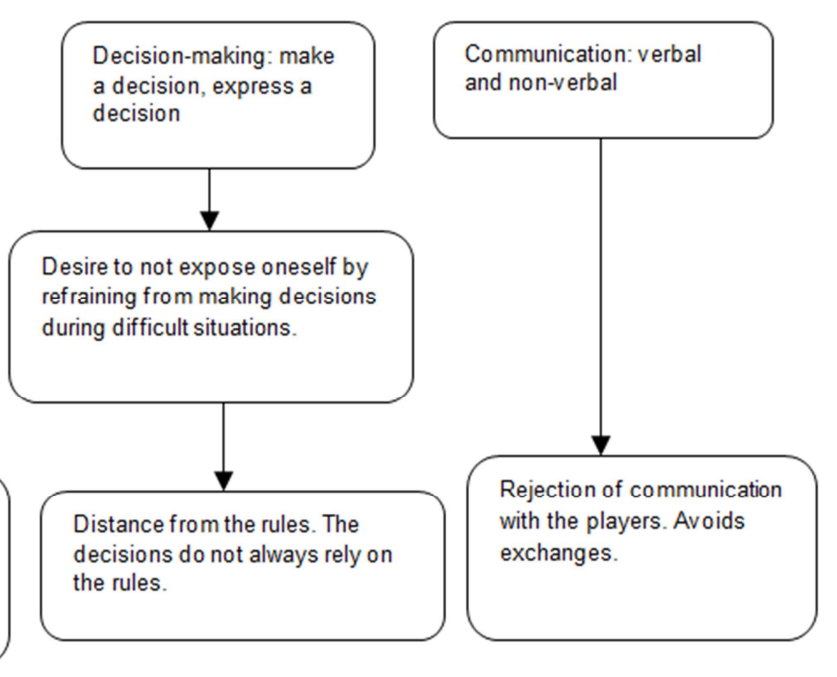

Figure 1. Schema of the activity of consensual referees. Olympe, a G1 group referee, talks about the need to be in the middle of the situations and the propensity to anticipate conflicting interactions:

'We need to be where things happen, to enter the fray, as they say. This gives us at least the ability to act before a problem appears. That's the referee's mission. We must be capable of anticipation... to predict the events.'

Olympe, 49 years old, G1 referee

The referee is near the location of the game and the interactions on the pitch. He relies on two tools to construct his physical activity: motions along the directions of the game - lateral, forward and backward motions, and small, lateral motions in zigzag, like a wiper. The physical activity is deployed toward communication and the prevention of 
behaviours. The goal is to make the players understand what is allowed and what is not.

\subsubsection{My Motions Always Serve a Purpose"- Wilfried, 50 Years Old}

The physical motions serve the regulation of interactions. By establishing his physical presence during a situation, the referee uses communication tools. The motion is deliberate, it is constructed, it is justified. It allows to convey information to the players or to express preventive messages. Wilfried, a G1 group referee, underlines the importance and the meaning that he gives to his motions in order to communicate with the players:

'My motions always serve a purpose. They must understand why I moved, why I came extremely close to them, or why I looked into their eyes. We are constantly expressing messages, and it's up to them to receive them or not...'

Wilfried, 50 years old, G1 referee

The referees rely on multiple techniques to make their motions meaningful. The "sports judges" can use the notion of "distance". According to the notion of proxemics (Hall, 1971), there are four zones that can be used to communicate with the players, depending on the nature of the messages: the intimate distance (between 15 and $45 \mathrm{~cm}$ ), which implies an increased physical presence and an important sensory exchange; the personal distance (between 45 and $135 \mathrm{~cm}$ ) which is used to send a message to a specific player; the social distance (between 1.20 and $3.70 \mathrm{~m}$ ) usually for interactions with friends and colleagues, and the public distance (over $3.70 \mathrm{~m}$ ) when addressing a group or several people. The rule-following referees establish a special relationship with the players, and it relies on the use of distances. For instance, the more serious the offence, the smaller the distance between one of the two referees and the player. Motions help the referee to win credibility with the players. Two circumstances during a match between Racing and Association Sportive, with Nordine (36 years old) and Mohammed (37 years old) as referees, provide a concrete depiction of the meaning given to motions:

'04'51: the activity around the pivot area increases. A92 does not hold the ball, and slightly pushes B66, his direct opponent, to prevent him from gaining an advantage in his area. B66 then tries to gain an advantage on A92 by pushing him and elbowing him. A92 turn around and stares at B66. He pushes B66, a bit more forcefully. The goal referee intervenes. He whistles several times, runs toward the two players and utters a few words toward them. The goal referee makes a short but intense intervention. He enters the two players' social distance.'

Explanation: "from the beginning, I knew that I would have to intervene. I just waited for the right moment to do it based on the context. I think we should act in these kinds of situations because that's the nature of the pivot players... they try... they provoke... they fight... We have to assert ourselves to prevent the situation from blowing up. I think the intervention was needed. We would have been in trouble if we didn't act."

Explanation given by Nordine, G1 referee.

07: 03: player B3 gets past winger A2 on A2's defensive sector, and has an opportunity to score. A2 is beaten in the defensive duel and slightly pushes B3. The referees let the action unfold. B3 scores and team A must throw off. The goal referee trots toward A2, enters the player's social distance, tells him a few words, then returns to his initial position.

Explanation: "Although the offence did not deserve a direct punishment, I think it is useful to walk past him and tell him that what he did was borderline. The player often likes that you warn him before punishing him, and that gives you credibility. And that's refereeing; you constantly try to gain credibility."

Explanation given by Mohammed, G1 referee'

Research notes, match between Racing and Association Sportive (PROD2)

Motions, coupled with anticipation, allow a reduction of the risks of aggressive behaviours punished by the rules. The referees attempt to anticipate by predicting how the game situations will unfold. They develop predicting tools to reduce uncertainty. Physical performance and anticipation serve the rules effectively only if the referees make consistent decisions that abide by the rules. Therefore, they develop a decision-making activity adapted to the requirements of the institution of refereeing.

\subsection{3. (...) Our Decisions Do Not Come out of Nowhere"- Cyril, 30 Years Old}

The referees try to exhibit an activity that respects and abides by the rules. They rely on objective criteria to ensure their consistency and to give the players the means to understand the decisions. The later refer to a specific rule as well as to the tools that favour decision-making. The criteria for disciplinary actions are for instance set out in the referee's booklet. "Rule 8: Fouls and Unsportsmanlike Conduct" lists the behaviours that may result in a personal punishment. The rule-following referees systematically follow the rules when they apply to behaviour. The rule is reinforced by formal criteria. Cyril, a G2 group referee, explains that his decisions are almost always taken based on objective and formal criteria:

'As much as possible, we try to base our decisions on criteria. In short, we must be capable of demonstrating that our decisions do not come out of nowhere. It is a matter of credibility.'

Cyril, 30 years old, G2 referee

The "men in black" try to make the players understand what offences they can tolerate, and what others are punished. They explain what can be negotiated and what are not. They use formal criteria when making decisions in order to achieve clarity and consistency. The requirement of consistency is illustrated on several levels: the referees make similar decisions on identical circumstances. A specific foul always result in the same punishment, whether it's a sports punishment (free throw or 7metre throw) or a personal punishment. The need for 
consistency is a core element that structures the activity of the referee. The identity of the punished team, the score, the stakes of the match - both on a sport perspective and outside of sport, do not matter. Thierry, a G1 group referee, emphasizes the significance of consistency when directing a match until its end:

'Beyond reproach... you have to be beyond reproach if you can... That means the same foul always results in the same punishment, for both teams... you must be consistent, even if you make mistakes sometimes. It's ok if you are consistent... otherwise it becomes hard to control the game until its end.'

Thierry, 32 years old, G1 referee

We understand the central position of the rules and of the consistency principle for the rule-following referees. The division of tasks and the gathering of relevant information help in developing the type of decision-making activities previously described.

\subsection{4. (...) Complement Each Other in Order to Monitor the Pitch"- François, 30 Years Old}

The decisions taken in the field rely on observable clues that ensure the compliance with the rules. The division of tasks between referees is planned and calculated to ensure total coverage and optimal monitoring of the pitch. François, a G2 group referee, explains why having referees that complement each other is necessary for the gathering of information needed to make decisions:

'We can rely on each other and perform specific tasks. That allows us to be more effective... We are looking for the small things that help us take a decision. The rest doesn't matter to us... It also allows us to complement each other in order to monitor the pitch'.

François, 30 years old, G2 referee
The division of tasks help the referees gather the maximum of clues. It helps avoid contradicting decisions or both referees whistling, while encouraging cooperation and effective choices. Even though each referee pair has its own way of dividing the tasks, there are some constants. The goal referee gathers information right outside the goal area, during the "fighting" periods between attacking pivots and defending pivots, in the wing sector nearest to the goal referee, when a defensive or offensive player enters the goal area, and while remaining alert on any obvious goal opportunity that could result in 7-metre throw decisions. The field referee gathers information on the game in the other areas of the pitch and during transition periods, on plays between the 6-meter zone and the 9-meter zone, in the areas closest to his position, and during "man-toman" defences.

\subsection{5. (...) Get Him to Understand Our Approach"- Clément, 26 Years Old}

Communication is an instrument of regulation and prevention. It can be verbal or non-verbal. "Non-verbal" communication refers to the use of distances, gestures, stares, postures, attitudes, motions, whistle signals... The list is not comprehensive but it shows that there are countless tools that can be used. Verbal and non-verbal communications can be combined. Communication ensures that the foul is made public, that everyone understands the boundaries of what is allowed. It helps to "sweeten" the decision and to deploy an actual "preventive" strategy. The rule-following referees thus favour taking risks and using instruments of preventions instead of going into fullrepressive mode.

\section{RULE-FOLLOWING REFEREE}
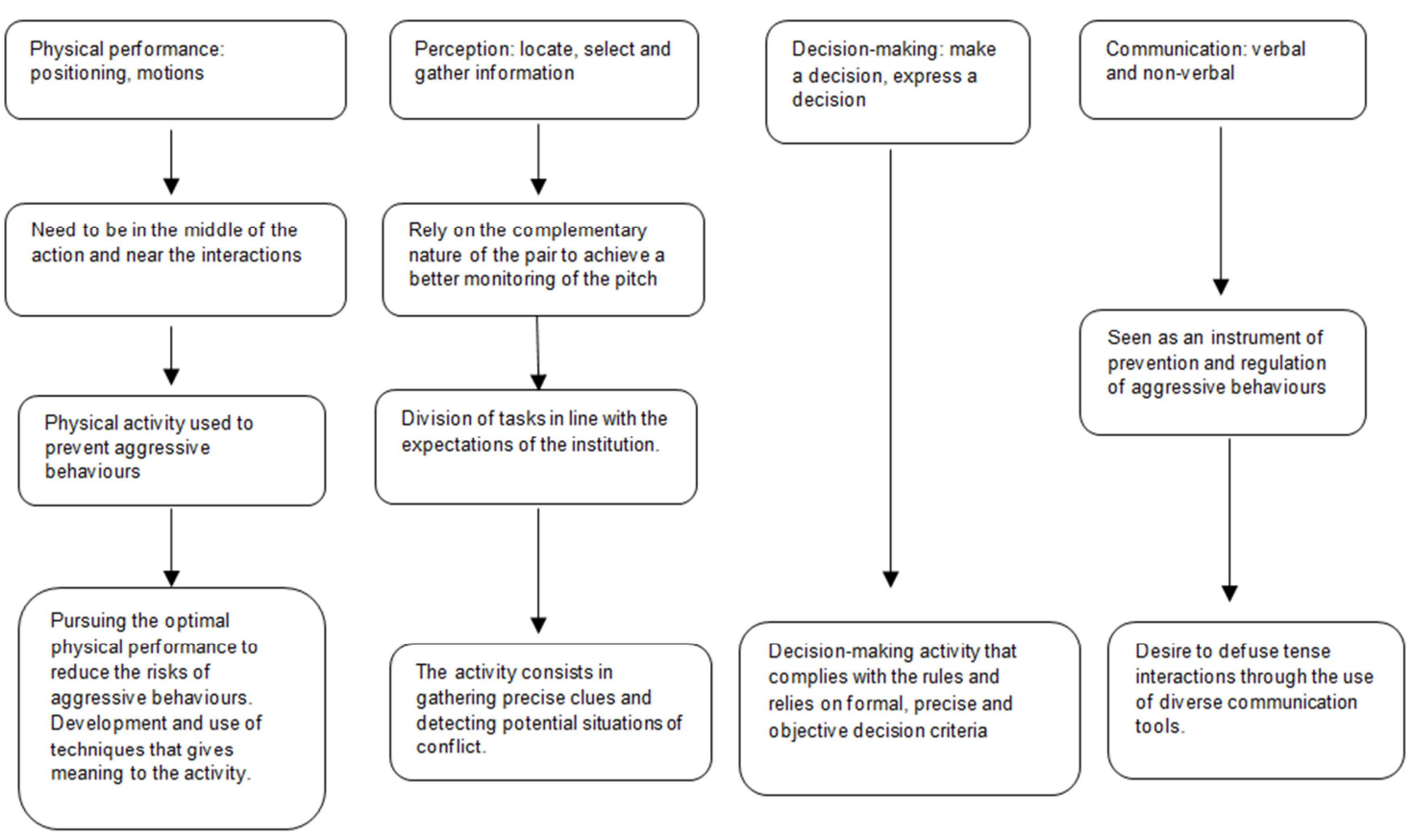

Figure 2. Schema of the activity of rule-following referees. 
The components used for communication are appropriate to the principles set out by the training reference document of elite referees. The "men in black" have the following tools: space, postures, attitudes, face expressions and gestures, gazes or voice signals. There are also other instruments, such as the motions; the verbal messages to explain why such player has crossed the limits of acceptable behaviours; the use of the wide array of disciplinary actions, the modulation of the whistle blows that help differentiate between an offensive foul and a defensive foul or to highlight a difference of seriousness of the offences; or the use of gestures and body language.

Communication helps to defuse tense interactions. It is even more important at the beginning of the match, when the first referee-player interactions can help the referees assert their decisions and gain credibility. The referees thus want the players to understand their decisions, as Clément, a G2 group referee, explains:

'We walk near the player, glance at him, we are entering his intimate area... the goal is to get him to understand our approach. We believe that the game will go well if the layers understand how we officiate. So we do everything so that they can learn what they can or cannot do.'

Clément, 26 years old, G2 referee

The "men in black" use technical tools to construct their refereeing activity. These tools allow them to be better understood by the players.

\subsection{The Perceptive Referees}

\subsubsection{We Can Offer Something New in Every Circumstance" - Lilian, 44 Years Old}

The "sports judges" that belong to this profile develop a physical activity that allows them to adapt to the circumstances in the pitch. The circumstances orient and determine their positioning and their motions. They depend on the context of the match and its successive situations. Therefore, several types of positions and motions can be observed during the same game. We can record dynamic positioning and attitudes at times, then static and reserved at other times. Some circumstances require the referee to come near the actions in order to act, while others require more distance from the game: man-to-man defences, transition phases or a play across the pitch. The "men in black" decide depending on the situations and develop a physical activity appropriate to the game. The refereeing activity swings between anticipation and reaction. As such, the referees may use anticipation in order to better handle some circumstances and react only after the event has passed by giving a personal punishment. The physical performance is constructed between strong presence and involvement, and distance and withdrawal. Above all, it adapts to the circumstances of the game, as explained by Lilian, a G1 group referee:

We can offer something new in every circumstance. We really want to adapt to what the players are doing... We did not come with a well-defined notion of refereeing or even of handball... we see how the events are unfolding and we adapt to what happens. We do not come with a set of standard responses.

\section{Lilian, 44 years old, G1 referee}

The referee's positions and motions help to prevent illegal behaviours and to communicate with the players. Unlike the other profiles, the "men in black" run toward the place where the offence was committed not when there is a situation of conflict, but when their intervention brings some benefits to the game.

\subsubsection{Referees Who Observe, Question and Offer Solutions}

The decision-making process of perceptive referees varies depending on the circumstances. They do not necessarily stick to the rules. A stronger attention is given to what happens in the pitch. The "sports judges" try to decrypt and read the balance of power in order to provide decisions appropriate to the situations. The referees use the OQO acronym (standing for Observe, Question, Offer solutions) to define their activity. They observe a situation to evaluate the multiple dimensions of the interaction, question themselves to describe the problem that results from the evaluated situation, and offer a solution. The "men in black" may decide to not enforce a rule if they deem it inappropriate in light of the specific context. Two circumstances during a match, along with the explanations of the referees, help us show how important the situation on the pitch is for them:

Situation: 03'28: player A3 manages to breach between two defenders B2 and B7. B2 turns back once he lost his duel, and pushes A3, who manages to score a goal while stepping a foot into the goal area. Theoretical decision according to the rules: a 7-metre throw is required as the goal cannot be awarded because of an offensive foul (the player entered the goal area). Player B2 risks a personal punishment. Decision taken by the referees: the referees award the goal and give a 2-minute suspension to B2 as deferred punishment. Explanation: "even though the rules do not state it, we had to award the goal. If only for the people who were in attendance and who did not care whether the player had his foot inside the goal area or not. But above all, considering the seriousness of the offence... awarding the goal and then giving a punishment, that's a double sentence, and we had to leave a mark on people's mind."

Situation: 07'17: winger A2 is pushed by his opponent, defender B14. A2 is unable to continue his action and to get a shooting opportunity. He was doing a jump shot when the impact occured, throwing off his balance and making him fall on the ground. Theoretical decision according to the rules: the referees must give a personal punishment to B14 and a 7metre throw to team A. Decision taken by the referees: the goal referee gives a 7-meter throw to team $\mathrm{A}$ and a 2-minute suspension to B14. Explanation: "I was ready to give him a warning (yellow card) at first, then I saw that the coach started to get agitated... so I gave him 2 minutes. That gave us a moment of peace. And he went to sit on the bench."

Excerpts of research notes, match between Athletic Club 
and Université Club, with Tanguy (47 years old) and Damien (48 years old) as referees.

The referees who belong to this profile develop a vision of personal punishment that opposes the random distribution by the consensual referees and the systematic use of punishments by the rule-following referees. They believe that not all offences should lead to disciplinary actions even if the rules state otherwise. They sort out the fouls and only punish the most serious ones. They rely on a period of observation to build their refereeing activity. Should the players display a good mind-set during the period of observation, the referees will refrain from going into full-repressive mode. The referees use a preventive strategy based on communication. If the mind-set and the physical interactions worsen, the referees adopt a new strategy toward a more repressive approach. The period of observation is essential for the referees who belong to this profile in order to detect the players likely to commit offences.

The "men in black" adapt to the game and the players. They handle a player that seems likely to transgress the rules by breaking the distances, alternating between punishment and prevention, modulating the whistle blow, using gestures, uttering words. They rely on varied strategies to anticipate and reduce the risks of conflicting interactions. The type of communication in use here is close to those of the rule- following referees. The difference between the two profiles lies in the management of personalities. Perceptive referees pay a special attention to the potential troublemakers, as evidenced by the words of Jean-Hubert and Hilaire, group G2 referees:

'We pay more attention to the dudes that may explode at any time. We are still attentive to the others, but a bit less... It's a two-tier refereeing of sorts, but at least that reduces the odds of the match going wrong'.

Hilaire, 44 years old, G2 referee

'Once we've identified the dude, then it begins... We'll go talk to him, approach him, watch him. The more we intervene on him, the more he will feel cornered. So that means he will feel that there's not much he can do. We can control him in theory. We don't give him any leeway, and he knows it. The goal is to prevent him from going to the point of no return, and we won't let leave him alone. The match will be successful for us if everything is done to keep him relatively peaceful.'

Jean-Hubert, 46 years old, G2 referee

Behaviour regulation happens at two levels: a close attention to the players identified as potentially violent, with preventive activity and increased explanations, and a lower level of alertness toward the other players.

\section{PERCEPTIVE REFEREE}

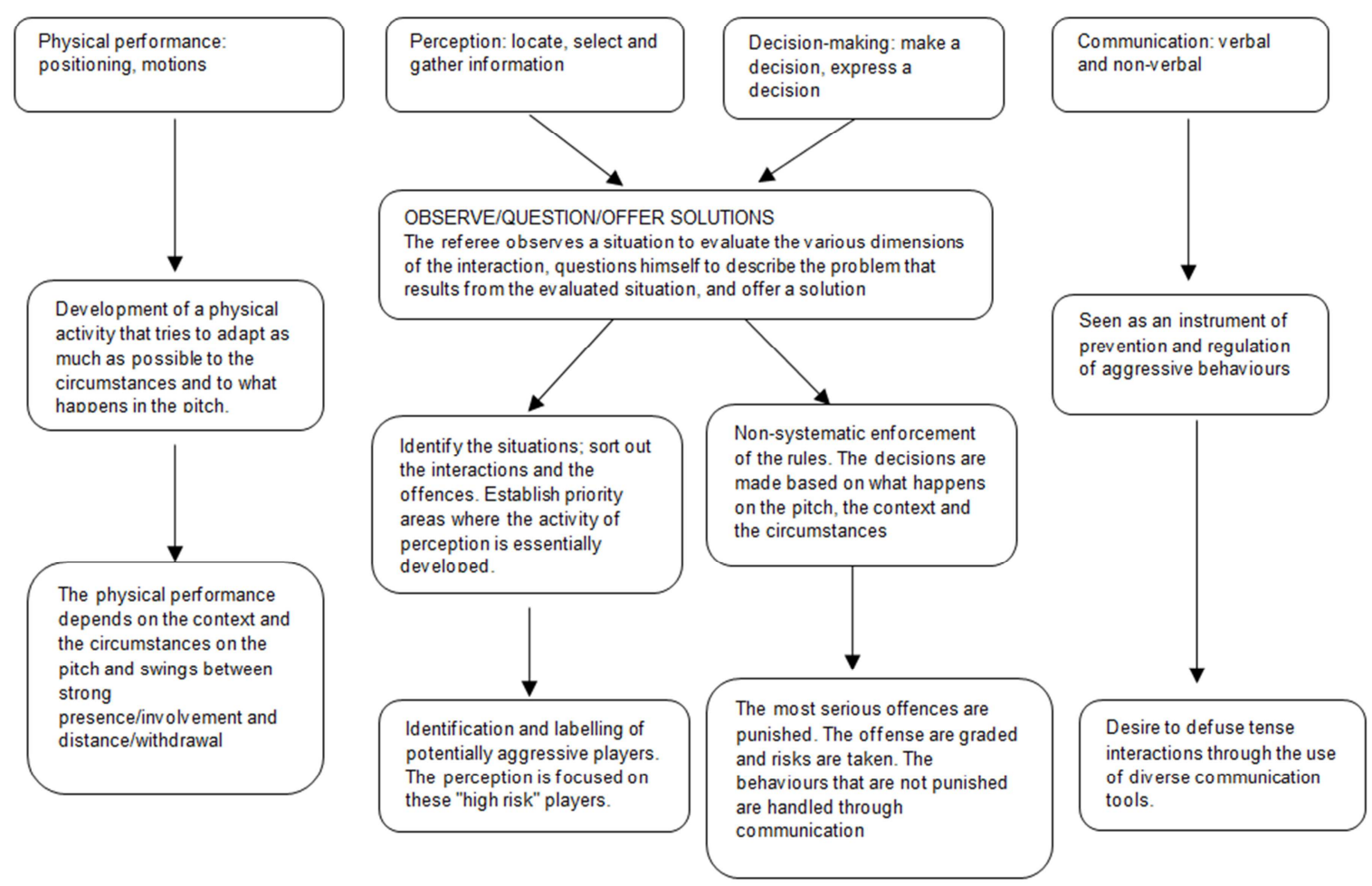

Figure 3. Schema of the activity of rule-following referees.

\section{Discussion}

We decided to adopt a quantitative approach that would allow us to evaluate, describe and understand the referees, their strategies and the tools and means that they deploy during their activity to deal with punishable aggressive behaviours. We developed three profiles: the consensual referees, the rule- 
following referees and the perceptive referees, taking into account the various components of refereeing. The decision to follow a more global approach of refereeing helps us to build profiles allowing the understanding of the activity of regulation of the "men in black".

Consensual referees resort to an approach outside the rules that does not focus on behaviour management. They bet on the players' ability to self-regulate and take a step back from the action. They deliberately disregard some of their duties to safeguard their credibility. It seems that the consensual referees contribute to the perpetration of fouls by refusing to deal with them, to prevent them or to explain them. By refraining from intervening during debatable circumstances, these referees may create frustration and contribute to the apparition of punishable behaviours. As a result, the interactions between players might become tense and lead to conflict.

Rule-following referees deploy a by-the-book strategy. They systematically respond to conflicting interactions and illegal behaviours with personal punishments. They seek consistency across all their choices: the same offence results in the same decision and the same punishment. The rulefollowing "men in black" seem more reassuring than the consensual referees. Yet the strategy of these "sports judges" may appear restrictive and stifle the players' expression. Sticking to the rules at all cost may lead the rule-following referees to harm the game. They may frustrate the players and trigger punishable behaviours and protests. Therefore, the rule-following players are sometimes giving punishments mistakenly or are too harsh in their decisions. This is a case of "false positive" [20]. The officials thus open the door to protests, abuses, aggressive behaviours...

The perceptive referees use a strategy that grants a major role to the pitch. They attempt to follow and enforce the rules, while still adapting to the circumstances of the games as much as possible. The referees employ preventive actions against the players identified as potentially violent and repressive actions against the most serious offences. However, by their wish to adapt as much as possible to the events in the field, they take the risk of actually moving away from reality. They may develop an approach that conflicts with the context and the mind-set of the game, which brings a context more favourable to punishable behaviours.

\section{Conclusion}

The choice of a more global assessment of refereeing helped to clarify, to describe in finer details the regulatory activity of the referees and to develop a systematic knowledge of the strategies, behaviours and attitudes used against aggressive behaviours. It provides the means to build knowledge that would not have been available using a segmented approach. In the end, the global approach helps prove that the referees have multiple responses to aggressive behaviours: physical performance, perception, decision-making and communication. However, it should not lead us into an all-out race toward taking into account every contextual element and every situation. Studying the activity of the referee in its totality seems an idealistic and even unrealistic endeavour. It is necessary to take into account the other referees that are coconstructing the activity [30] as well as other elements that may be neglected but which affect the refereeing: the training, the personal background and the career, the key periods of the life of the individual and so on... Does that imply that we must give up on the idea of grasping the complexity of the activity of the referee? This research wishes to show that adopting a more global approach of refereeing allows approaching reality as it unfolds. The project of assessing the complexity must not be given up, it may help us go beyond the segmenting sociological perspectives.

\section{References}

[1] D'HAINAUT L. (1988). Des fins aux objectifs de l'éducation, Bruxelles, Labor, fifth edition, p. 472.

[2] DE KETELE, J-M. (1985). Docimologie, introduction aux concepts et aux pratiques. Cabay, p. 24

[3] MEIRIEU, P. (1991). Apprendre... oui, mais comment ?, Paris, ESF éditeur, 8th edition, p. 181.

[4] DA SILVA, A., PEREZ, R., FERNANDES, L. (2007). 'Determining physical capacity and anthropometric profile of soccer woman referee'. Fitness and Performance Journal (Online Edition), 6 (1), 45-52.

[5] ELSWORTHY, N., BURKE, D., SCOTT, B., STEVENS, C., DASCOMBE, B. (2014). 'Physical and decision-making demands of Australian football umpires during competitive matches'. Journal of Strength and Conditioning Research, 28, 3502-3507.

[6] KAY, B., GILL, N., D. (2003). 'Physical demands of elite Rugby League referees: part one - time and motion analysis'. Journal of Science and Medicine in Sport, 6, 339-342.

[7] MASCARENHAS, D., BUTTON, C., O'HARE, D., DICKS, M. (2009). 'Physical Performance and Decision Making in Association Football Referees: A Naturalistic Study.' The Open Sports Sciences Journal, Volume 2, ISSN: 1875-399X.

[8] CATTEEUW, P., Gilis B., WAGEMANS, J., HELSEN, W. (2010). 'Soccer football Offside decision making of assistant referees in the English Premier League: impact of physical and perceptual-cognitive factors on match performance'. Journal of Sport Sciences, 28, 471-481.

[9] OUDEJANS, R., R., D., BAKKER, F., C., VERHEIJEN, R., GERRITS, J., C., STEINBRUCKNER, M., BEEK, P., J. (2005). 'How Position and Motion of Expert Assistant Referees in Soccer Relate to the Quality of their Offside Judgments during Actual Match Play'. International Journal of Sport Psychology, 36 (1), 3-21.

[10] PIZZERA, A., RAAB, M. (2012). 'Does motor or visual experience enhance the detection of deceptive movements in football?' International Journal of Sports Science \& Coaching, 7, 269-284.

[11] MORRIS, P., LEWIS, D. (2009). 'Tackling Diving: The Perception of Deceptive Intentions in Association Football (Soccer)'. Journal of Nonverbal Behavior. 0191-5886 (Print) 1573-3653 (Online). 
[12] CHALKLEY, D., MACMAHON, C., BALL, K. (2013). 'Predicting ball flight in Cricket from an umpire's perspective'. International Journal of Sports Science \& Coaching, 8, 445-454.

[13] LARKIN, P., BERRY J., MESAGNO, C., SPITTLE, M. (2011). 'Video-based training to improve umpire decisionmaking'. Journal of Science and Medicine in Sport, 14 (S1), 88 .

[14] MAC MAHON, C., HELSEN, W., STARKES, J., CUYPERS, K., WESTON, M. (2007). 'Decision-making skills and deliberate practice in elite association football referees'. Journal of Sport Sciences, 25, 65-78.

[15] WILSON, V. (1977). "Objectivity and effect of order of appearance in judging synchronized swimming meets". Perceptual and Motor Skills, 44, 295-298.

[16] WHISSEL, R., LYONS, S. WILKINSON, D. WHISSEL, C. (1993). "National bias in judgements of Olympic-level skating." Perceptual and Motor Skills, 77, 355-358.

[17] BALMER, N., NEVILl, A., LANE, A., WARD, P., WILLIAMS, M., FAIRCLOUGH, S. (2007) "Influence of Crowd Noise on Soccer Refereeing Consistency in Soccer." Journal of Sport Behavior, 2: 130-145

[18] DOWNWARD, P., JONES, M. (2007). "Effects of crowd size on referee decisions: Analysis of the FA Cup." Journal of Sports Sciences, 25, 1541-1545.

[19] NEVILL, A., BALMER, N., WILLIAMS, 2002, "The influence of crowd noise and experience upon refereeing decisions in football". Psychology of Sport and Exercise, Volume 3, Number 4, October 2002, pp. 261-272 (12)

[20] UNKELBACH, C., MEMMERT, D. (2010). "Crowd noise as a cue in referee decisions contributes to the home advantage". Journal of Sport \& Exercise Psychology, 32, 483-498.

[21] REYNES, E., CANOVAS, S., FERRAND, C., PANTALEON, N. (2008). 'Emotional consequences of referee's mistake among soccer players: exploratory study'. Psicologia \& Sociedade, 20 (1), 5-15.

[22] SIMMONS, P. (2010). 'Communicative displays as fairness heuristics: strategic football referee communication'. Australian Journal of Communication, 37, 75-94.

[23] DICKSON, S., 1999, "The relationship of officials with players and coaches." The Sport Educator, 11, 35-37.

[24] CUNNINGHAM, I.., SIMMONS, P., MASCARENHAS, D., REDHEAD, S. (2015). "Exploring player communication in interactions with sport officials." Movement \& Sport Sciences - Science \& Motricité, 87, 79-89.

[25] BOYKO, R; BOYKO, A; BOYKO, M, 2007,'Referee bias contributes to home advantage in English Premiership football". Journal of Sports Sciences, Volume 25, Number 11, September 2007, pp. 1185-1194 (10)

[26] BALMER, N., NEVILL, A., LANE, A, 2007,'Do judges enhance home advantage in European championship boxing?" Journal of Sports Sciences. 23: 409-416

[27] ARENI, C. S., 2014, "Home advantage, rivalry, and referee bias in representative rugby." Sport, Business and Management: An International Journal, 4, 142-157. http://dx.doi.org/10.1108/SBM-06-2012-0022
[28] OGIEN A. (1995), Sociologie de la déviance, Presses Universitaires de France.

[29] NUYTENS W, (2011). L'épreuve du terrain. Violences des tribunes, violences des stades, Rennes, Presses Universitaires de Rennes, coll. Des sociétés.

[30] RIX-LIEVRE, G., BOYER, S., COUTAREL, F., LIEVRE, P. (2014). 'Refereeing performance: From study to development'.@ctivités, 11 (1),86-104.

[31] RIX-LIEVRE, G., BOYER, S., TERFOUS, F., LIEVRE, P., COUTAREL, F. (2015). 'The Co-Production of Top-Level Refereeing Performance: The Case of Rugby'. Sociologie $d u$ travail, 57, pp. 496-515.

[32] RIX - LIEVRE, G., GENEBRIER, V. (2011). 'Interactions players-referee during a soccer match: understandind how altercations appear or not'. Movement and Sport Sciences Science \& Motricité, 72, 27-33.

[33] COLLARD, L. (2004). Sport \& agressivité. Éditions DésIris.

[34] COUlOMB, G., RASClE, O., PFISTER, R. (1999). «Comportements d'agression et motifs de participation en sports collectifs: influence du sexe et du type de pratique», STAPS, 49, 33-46.

[35] BARON, R. A., RICHARDSON, DR. (1994). Human Aggression, $2^{\text {nd }}$ ed. New York: Plenum Press.

[36] BERKOWITZ, L. (1983). « The Goals of Aggression », in FINKELHOR, D. (dir.), The Dark Side of Families. Beverly Hills: Sage.

[37] KARLI, P. (1987). L'homme agressif. Paris: Odile Jacob.

[38] CUSSON, M., PROULX, J., (1999). «Que savons-nous sur la violence criminelle?» in, Les violences criminelles, chapitre 1 , pp. 11-40. Québec: Les Presses de l'Université Laval, 353 pp.

[39] TEDESCHI, J. T., FELSON, R. B. (1994). Violence, Aggression and Coercive Actions. Washington, D. C.: American Psychological Association.

[40] NUYTENS, W., PENIN, N. (2010). 'The uneven distribution of violences in amateur sports: Why there more than somewhere else?' Science et motricité, 71, 49-54.

[41] HAWKINS, R., D., FULLER, C., W. (1996). Risk assessment in professional football: an examination of accidents and incidents in the 1994 World Cup Finals. British Journal of Sports Medicine, 30: 165-170.

[42] ANDERSEN, T., ENGEBRETSEN, L., BAHR, R. (2004). Rule violations as a cause of injuries in male Norwegian professional football: Are the referees doing their job? American Journal of Sports Medicine, 32, 62-68.

[43] THOENIG, J-C. (1998). «L'usage du concept de régulation», Revue droit et société, vol 24, 19.

[44] DE TERSSAC G. (2012). «La théorie de la régulation sociale: repères introductifs». Interventions économiques: papers in Political Economy, pp. 1-16.

[45] REYNAUD, J.-D. (1997). Les règles du jeu. L'action collective et la régulation sociale. Paris, Armand Colin.

[46] NUYTENS, W., PENIN N. (2015). "La place des arbitres dans les mécanismes de régulation". Jurisport, revue juridique et économique du sport, 149. 
[47] MASCARENHAS, D., COLLINS, D., MORTIMER, P. (2002). The Art of Reason Versus the Exactness of Science in Elite Refereeing: Comments on Plessner and Betsch (2001)" Journal of Sport and Exercise Physiology, 24 (3)

[48] ACKERY, A. D., TATOR, C. H., SNIDER, C. (2012). 'Violence in Canadian amateur hockey: the experience of referees in Ontario'. Clinical Journal of Sport Medicine, 22, 86-90.

[49] KITCHENS, C. (2014). Identifying changes in the spatial distribution of crime: evidence from a referee experiment in the National Football League. Economic Inquiry, 52, 259-268.

[50] WEBB, T., THELWELL, R. (2015). "He's taken a dive": Cultural comparisons of elite referee responses to reduced player behaviour in association football. Sport, Business and Management: An International Journal, Vol. 5 Iss: 3, pp. 242 -258 .

[51] CUSSON, M., (1983). Contrôle social du crime. Paris: Les Presses universitaires de France, $342 \mathrm{p}$.

[52] MONTARGOT, N. (2016), 'Gastronomy and excellence at the heat of identity building of the best workers in France' in Question (s) de Management, 2016/3, n 14, p. 77-87.

[53] BONNET, E. (2004). 'Restaurant Critics: Some Characteristics of an Expert Activity'. Sociétés contemporaines, no 53 (1), 135-155. doi: $10.3917 /$ soco.053.0135.

[54] FASSIN, D. (2011). La force de l'ordre. Une anthropologie de la police des quartiers, Le Seuil, Paris.

[55] MOLINO J., MOLINO-LAFHAIL R. (2003). Homo Fabulator. Théorie et analyse du récit. Léméac. Actes sud. pp. 249-280.

[56] DARGERE, C. (2014). L'observation incognito, entre œil de Caïn et œil de Moscou: réflexions déontologiques et idéologiques autour de «la clandestine», Recherches qualitatives, Vol. 33 (1), pp. 41-63.

[57] ARBORIO, A-M., FOURNIER, P., \& DE SINGLY, F. (2005). L'observation directe (2nd ed.). Paris: Armand Colin.

[58] HUGHES, E., C. (1971). The Sociological Eye: Selected papers, Chicago, Aldine.
[59] PANDRAUD, N. (2013). 'A theory of observation in situ. Story, situation and perception'. SociologieS [online], First papers, published online on 20 February 2013, accessed on 09 April 2017. URL: http://sociologies.revues.org/4315.

[60] BECKER, H. S. (2003). Inférence et preuve en observation participante. Fiabilité des données et validité des hypothèses. In D. Céfaï (Ed.), L'enquête de terrain (p. 350-362). Paris: La Découverte.

[61] COENEN-HUTHER J. (2003), "The Ideal Type as an Instrument of Sociological Research", Revue française de sociologie, 3/2003 (Vol. 44), p. 531-547.

[62] ROCHER, G., (1993). " Type idéal » in André-Jean Arnaud, Jacques Commaille et al. (editors). Dictionnaire encyclopédique de théorie et de sociologie du droit. Libraire Générale de droit et de Jurisprudence, pp. 628-630 [2nd edition].

[63] DANTIER B. (2004). Les « idéaltypes » de Max Weber, leurs constructions et usages dans la recherche sociologique. Les catégories de la sociologie T. 1 de Max Weber, Economie et société, 28-29.

[64] HIRSCHMAN, A. (1970). Exit, voice and loyalty. Responses to decline in firms, organizations, and states. Cambridge: Harvard University Press.

[65] HAGEDOORN, M., VAN YPEREN, N., VAN DE VLIERT, E., BUUK, B. (1999). "Employees' reactions to problematic events: a circumplex structure of five categories of responses, and the role of job satisfaction. Journal of Organizational Behavior, 20 (3), 309-321.

[66] WITHEY, M., COOPER, W. (1989). "Predicting exit, voice, loyalty and neglect". Administrative Science Quarterly, 34 (4), 521-539.

[67] RUSBULT, C., FARRELL, D., ROGERS, G., MAINOUS III, A. G. (1988). "Impact of exchange variables on exit, voice, loyalty and neglect: an integrative model of responses to declining job satisfaction", Academy of Management Journal, 31 (3), 599-627.

[68] SAINSAUliEU, R. (1996). L'identité au travail. Paris, Presses de Sciences Po.

[69] MERTON, R. K. (1949). Social Theory and Social Structure, Free Press. 